\title{
Research on anti-scourability of slope eroded Soil
}

\author{
Liu Xinchun ${ }^{1}$, Kang Yongde ${ }^{2 *}$, Chen Hongna ${ }^{3}$, Lu Hui ${ }^{4}$ \\ 1.Institute of Desert Meteorology, CMA, Taklimakan Desert Meteorology Field Experiment Station of CMA, Xinjiang \\ Laboratory of Tree Ring Ecology, Key Laboratory of Tree-ring Physical and Chemical Research of China \\ Meteorological Administration, Urumqi 830002, China; liuxch@idm.cn; \\ 2.State Key Laboratory of Eco-hydraulics in Northwest Arid Region of China, School of Water Resources and \\ Hydroelectric Engineering, Xi'an University of Technology, Xi'an 710048, China; kyd0115@yeah.net \\ 3.Department, Urumqi Environmental Monitoring Center, Urumqi 830001, China; liux-inchun2001@163.com \\ 4.Key Laboratory of Ecology of Rare and Endangered Species and Environmental Protection (Guangxi Normal \\ University), Ministry of Education, Guilin 541004, China; College of Environment and Resources, Guangxi Nor \\ mal University, Guilin 541004, China
}

\section{Abstract}

【Purpose】 Soil aggregates are of great significance to soil and water conservation and ecological environment construction in arid area of northwest district. 【Methods】 Exploring the effects of different vegetation includes types and land use methods on the stability of soil aggregates in the Loess Plateau, and provide reference for the rational use and management of land, also the improvement of soil structure in the region. Select 9 types of samples of 0-30 cm of typical soil plots as the research objects, compare and analyze the particle size index, stability differences and anti-erodibility of soil aggregates under various vegetation cover. 【Results】 The results show that $P$ value, MWD value, GMD value, D value, and AI value of the $0-10 \mathrm{~cm}$ surface soil all show the maximum value. As the depth increases, the size distribution of the above index values of each soil sample in the $10-20 \mathrm{~cm}$ and $20-30 \mathrm{~cm}$ layers is different; $\mathrm{P}$ value in the $0-30 \mathrm{~cm}$ depth layer is linearly positively correlated with the AI value and MWD value, and linearly negatively correlated with the $D$ value. The correlation coefficient $R$ between each variable is in the range of $0.78-0.97$, and the $D$ value reflects the Loess Plateau area stability and erosion resistance of soil aggregates better. GMD and MWD value show an exponential relationship, the correlation coefficient $R$ value of $10-20 \mathrm{~cm}$ height layer is 0.46 ; AI and MWD value in $0-10 \mathrm{~cm}, 20-30 \mathrm{~cm}$ height layer have a power function relationship, $10-20 \mathrm{~cm}$ height layer has a polynomial function, the correlation coefficient $\mathrm{R}$ value is 
0.97. The scour coefficient of different soil samples has a high degree of dispersion, the maximum CV value is 1.92 , and the minimum value is 0.49 .【Conclusions】 The results of this study can provide a theoretical basis for the ecological and hydrological benefit evaluation of slope erosion control and vegetation restoration on the Loess Plateau.

Keywords Soil anti-scourability; Soil erodibility; Artificial simulated rainfall; Soil aggreg ates; Erodibility

\section{Highlights}

$>$ The $\mathrm{K}$ value of soil erodibility is one of the important factors to calculate the amount of soil erosion.

$>$ Soil aggregates play a key role in the differences of soil structure at small watershed scale.

$>$ Provide reference for the Loess Plateau and other areas with similar conditions.

\section{Introduction}

Over the past decade, with the implementation of ecological management projects such as returning farmland to forests and grasslands, closing mountains , prohibiting grazing, and protecting natural forests, the ecological environment has improved significantly. However, due to the special topography of the Loess Plateau, soil erosion is still the main ecological problem in the region. (Yoder R E, et al ,1936).Soil erosion first occurs in the surface of the soil. Therefore, the stability of the topsoil is very important ( $\mathrm{Li} \mathrm{Z} \mathrm{X,} \mathrm{et} \mathrm{al,} \mathrm{2005),} \mathrm{Soil} \mathrm{water-stable} \mathrm{aggregates} \mathrm{are} \mathrm{key} \mathrm{indicators}$ for evaluating soil structural stability, erosion resistance, and runoff generation. They also play an important role in the sustainable development and utilization of land, maintenance of productivity, and nutrient cycling. (Amezketa E ,et al,1999;Six J, et al, 2004; Bronic C J, et al, 2005; Zhou H, et al, 2012;). It is generally believed that the degradation of soil structure is mainly manifested by the decrease in the stability of soil aggregates(Pinheiro E F M,et al,2004 ). Soil aggregates are affected by vegetation types, planting years and farming methods, and also vary with land use patterns. Saifuddin M, et al (2015) believes that agricultural farming is the main factor that destroys the structure of the surface soil; (Pinheiro et al 2004) have shown that the content of soil aggregates decreases after grassland becomes agricultural land; Fattet, et al (2011) have found that the stability of agricultural soil aggregates is less than that of forest land significantly. Soil aggregates are the basic unit structure of soil and are important indexes for studying soli structure and anti-erosion 
ability (Six J, 2004). soil aggregates are formed by natural processes such as cementation (Shinjo et al., 2000).

Soil aggregate stability is one of the most important factors affecting soil erosion and soil structure. The soil aggregate stability was controlled by several soil primary characteristics, such as soil texture, clay mineralogy, contents of organic matter, which influence many soil properties, including soil porosity, hydraulic conductivity, water-holding capacity, and soil erosion process (Zhu et al., 2018). The stability of soil aggregates is affected by scour under different slopes and different flow rates, which leads to the difference in soil erosion rates.

Soil water-stable aggregates are the best indicator for soil anti-erosion ability. They are usually evaluated by three indicators: average weight diameter (MWD), geometric average diameter (GMD), and fractal dimension (D) of soil water-stable aggregates the stability of soil aggregates, and the particle size $>0.25 \mathrm{~mm}$ the water-stable aggregates are regarded as the most structural aggregates, and the higher the content, the stronger the erosion resistance of soil. Many soil erosion studies focus on the effects of runoff power, whereas much less attention has been paid to the effects of soil anti-scourability on water erosion rates. Soil erosion is a process, in which soil and other ground substances were destroyed, denudated, transported and induced deposition by water, wind, freezethaw and gravity acts in the land surface. In semiarid areas, soil erosion is a serious threat to land productivity and sustainability for natural and human-managed ecosystems (Su Z A, et al., 2010; Fu B J et al., 2011). Water erosion is one of the most important forms of erosion in soil erosion, and soil anti-scourability is the index that best reflects the process and law of regional soil erosion.In addition to absorbing and storing water and nutrients, plant roots can also provide stability to the plant itself, which means that the soil containing roots has resistance to wind and water attraction (Reubens et al., 2007). It is generally believed that the root system improves soil properties (such as soil cohesion, soil stability and shear strength) through its tensile strength, friction and adhesion characteristics, therebyimproving soil resistance to water erosion (Fattet et al., 2011; Ola et al., 2015; Saifuddin et al., 2015).

With the acceleration of ecological civilization construction, under the premise of revealing the law of slope erosion and soil erosion mechanism in the Loess Plateau, this article takes the soil from different typical forest and grass vegetation types as the research object to clarify the law of 
erosion resistance. Analyze the influence of the MWD, GMD, D, and P values of soil aggregates on the distribution and stability of soil water-stable aggregates, study the differences of soil waterstable aggregates under different vegetation types. However, the relationship between Water stability of soil aggregates and soil scour resistance is not clear. We attempt to clarify the following scientific issues: (1) How does the stability of soil aggregates change during rainfall process? (2) What is the contribution of waterstable aggregate content to the Soil and Water Conservation?

\section{Materials and methods}

\subsection{Study area and sampling design}

The landform type of the study site is a typical loess hilly and gully area. The soil type is mainly loessial soil with sparse vegetation. In the summer rainstorm season, soil erosion is serious and the surface is washed away by thousands of gullies. The average annual rainfall is mainly concentrated on July and August each year. The precipitation is $600 \mathrm{~mm}$, and the average annual potential evaporation is $1050 \mathrm{~mm}$. Common vegetation types mainly include Prunus davidiana Franch, Prunnus sibirica L, Hippophae rhamnoides Linn, Caragana Korshinskii Kom and Artemisia gmelinii and Bothriochloaischaemum L.

Based on common land use types in the Loess Plateau (arbor forest, shrub woodland, grassland and agricultural land). Selected prunus armeniaca, Hippophae rhamnoides, David peach, Caragana korshinshii, Thymus mongolicus, Potentilla bifurca, abandoned land and Grass 9 Typical vegetation plot, as shown in Table 1. Chose 5 points for each plot, and collected the original soil samples of $0-10 \mathrm{~cm}, 10-20 \mathrm{~cm}$, and $20-30 \mathrm{~cm}$ soil layers with a $100 \mathrm{~cm}^{3}$ ring knife at each point. After the soil was taken, backfilled layer by layer, and took each layer with 3 repetitions. Put it in an aluminum box to avoid squeezing, tried to keep the original shape of the soil sample, brought it back to the laboratory, and air-dry for testing.

In the laboratory, we broke the soil samples into 5 to 8 mmdiameter blocks according to the natural structure. Stones, plant roots and plant residues were removed from the soil samples, which were airdried at room temperature to preserve. Using the dry sieving method separted soil aggregates to obtain different aggregate size fractions, including $0.106-0.25,0.25-0.5,0.5-1,1-2$, mm. The soil bulk density was measured by the ring knife method (Hossain et al., 2015).

Table 1. Coverage of forest and grass vegetation in different sampling areas and sampling locations 


\begin{tabular}{|c|c|c|c|}
\hline No & Vegetation Type & Surface condition & Sampling Site \\
\hline 1 & Prunus armeniaca & $\begin{array}{l}\text { Artificial planting of Prunus armeniaca, their restored } \\
\text { years about } 11-20\end{array}$ & Gully bottom \\
\hline 2 & Hippophae rhamnoides & Without artificial disturbance. & Slope top \\
\hline 3 & David peach & $\begin{array}{l}\text { The surface is covered with David peach with a coverage } \\
\qquad \text { of } 99 \% .\end{array}$ & Mid-slope \\
\hline 4 & Caragana korshinshii & l & Gully bottom \\
\hline 5 & $\begin{array}{l}\text { Thymus mongolicus, Potentill acaulis, } \\
\text { Potentilla bifurca }\end{array}$ & Natural grassland & Mid-slope \\
\hline 6 & Abandoned land, & The surface is bare with a small amount of crust & Gully bottom \\
\hline 7 & Grass & Gully Erosion in the Remained Loess Area & Slope top \\
\hline 8 & $\begin{array}{c}\text { Xanthoceras sorbifolium, Amygdalus } \\
\text { mongolica }\end{array}$ & Artificial test aera & Gully bottom \\
\hline 9 & Robinia pseudoacacia & Artificial test aera & Gully bottom \\
\hline
\end{tabular}

\subsection{Calculation of soil anti-scouring}

Soil erodibility defined as the inherent susceptibility of soil to detachment and transport by rainfall and runoff. As an indicator of soil erodibility, the stability of soil aggregates is often used since aggregate breakdown is closely related to crusting that reduces the infiltration capacity drastically and increases runoff, thus leading to water erosion (Jacobs, M, et al,2018). The soil antiscour coefficients and soil erosion energy dissipation have been viewed as the most appropriate index for describing the stability of soils and can be calculated as follows:

$$
K_{\mathrm{c}}=\frac{Q t}{w}
$$

Where, $K_{\mathrm{c}}$ is soil anti-scour coefficients, L.min/g; $Q$ is erosion flow, L; $t$ is time, min; $w$ is soil quality after washing, g.

$$
K_{\mathrm{e}}=\frac{m v^{2}}{2 w}
$$

Where, $K_{\mathrm{e}}$ is erosion energy dissipation, $\mathrm{J} / \mathrm{g} ; m$ is erosion water quality, $\mathrm{kg} ; v$ is velocit $\mathrm{y}, \mathrm{m} / \mathrm{s} ; \quad w$ is soil quality after washing, $\mathrm{g}$.

\subsection{Calculation of waterstable aggregate content}

Karami et al. (2012), Sun and Lu (2014), Wang et al.(2015b), Zhu et al. (2017) and Yoder et al (1936) suggested that the waterstable aggregate content proportion $(\mathrm{P} ; \mathrm{mm})$, mean weight diameter (MWD; mm), geometric mean diameter (GMD; mm), fractal dimension (D) and aggregation index (AI) can be used to quantify soil aggregate stability (greater MWD and GMD 
values are associated with greater particle size agglomeration and greater stability; conversely, a smaller D leads to better structure and higher soil stability). MWD, GMD and D were calculated using the following formulas:

$$
\begin{aligned}
& P_{\mathrm{ma}}=\sum_{i=1}^{n} w_{i} / m_{T} \\
& M W D=\sum_{i=1}^{n}\left(w_{i} / m\right) d_{i} \\
& G W D=\exp \left(\sum_{i=1}^{n} r_{i} \log d_{i}\right) \\
& A I=\sum_{i=1}^{\mathrm{n}} Q_{i} r_{i} \\
& \frac{M\left(r<x_{i}\right)}{m_{T}}=\left(\frac{x_{i}}{d_{\max }}\right)^{3-D}
\end{aligned}
$$

where $d_{i}$ is the mean diameter $(\mathrm{mm})$ of the soil aggregate size fractions, $w_{i}$ is the proportion of the total soil in the ith size fraction $(\%),<M\left(r<x_{i}\right)$ is the mass of aggregates smaller than $\mathrm{xi}(\mathrm{mm}), m_{T}$ is the total mass of aggregates, and dmax is the maximum diameter of the soil aggregate size fractions.

In this study, before the analysis of variance, all data was tested for normality and homogeneity of variance. When the test of homogeneity of variance was passed, the Duncan method (confidence interval is within 95\%) was used to analyze the differences in multiple comparisons (Steel and Torrie, 1980). SPSS 24.0 software was used for all statistical analyses. The graphs and tables in this study were produced using Excel 2016, Origin 8.5.

\section{Results and analysis}

\subsection{Distribution characteristics of soil aggregates and soil stability}

As shown in Fig.1 (a). 9 types of samples have higher $\mathrm{P}$ values in the $0-10 \mathrm{~cm}$ soil layer, the more significant soil samples are 1 and 2 and 4. No matter which layer of soil samples, No. 2, No. 4, No. 7, and No. 8 have a higher P value than other samples. The $\mathrm{P}$ value of $10-20 \mathrm{~cm}$ of surface soil sample No. 2 reach more than $80 \%$. The P value of $10-20 \mathrm{~cm}$ on the surface of No. 2 soil sample is higher than $0-10 \mathrm{~cm}$, and the side reflects that the root system of this layer may have a stronger effect on soil improvement. The $P$ value of $10-20 \mathrm{~cm}$ and $20-30 \mathrm{~cm}$ of the soil sample No. 4 is higher than $0-10 \mathrm{~cm}$. It may be due to the scarcity of vegetation in the area where the soil sample No. 4 was collected and poor water conditions, which affected the development of aggregates of $0-10 \mathrm{~cm}$, 
while the development of aggregates of $10-20 \mathrm{~cm}$ and $20-30 \mathrm{~cm}$ are affected by the improvement of roots. The p value of the $10-20 \mathrm{~cm}$ soil layer of the No. 8 soil sample is higher than that of the 0 $10 \mathrm{~cm}$ and $20-30 \mathrm{~cm}$. The reason is similar to the No. 4 soil sample. In addition, the soil from the No. 8 soil sample collection area is due to the short restoration time of the planted vegetation. It's all caused by poor moisture conditions. The P value of each layer of the No. 9 soil sample is lower than $30 \%$, and the aggregate development is extremely poor. The preliminary analysis shows that it is because $0-10 \mathrm{~cm}$ is the loess parent material collapsed on both sides of the ditch slope, despite the development of vegetation and herbaceous plants. It is good, but the aggregate measurement results show that the soil formation process is very slow, which further proves that it is a collapsed loess parent material.

As shown in Fig.1 (b). The rule is more obvious for soil sample No. 1, that is, as the depth of the soil layer increases, the MWD value becomes smaller. The MWD value of other soil samples has no obvious law, the MWD values of soil samples No. 2, No. 4, No. 7 and No. 8 in the $10-20 \mathrm{~cm}$ layer are larger than the 10-20 cm layer, the reason may be the poor growth of the vegetation on the surface, and the deeper plant roots promote the development of aggregates more than the surface, it is found that the development variability of aggregates in the near-surface soil samples is quite different.

As shown in Fig.1 (c). The general rule of GMD agglomerate particle size is basically similar to the distribution rule of MWD, and at the same time, there is a certain correlation between them. Except for No. 2 and No. 4 soil samples, the GMD values of the 10-20cm layer are higher than the other two layers (0-10 and 20-30cm).

As shown in Fig.1 (d). The AI values of the 10-20cm layer of soil samples of No. 2, No. 4, No. 7 and No. 8 are still higher than the other two layers. The AI values of soil samples No. 6 and No. 9 are both low, indicating that the aggregate development in the early stage of ecological restoration is poor.

As shown in Fig.1 (e). The minimum D value of the aggregate particle size distribution is about 2.61, and the maximum value is about 2.98. Different from the above indicators, the smaller the D value, the larger the aggregate particle size, the larger the $\mathrm{D}$ value, and the aggregate the smaller the proportion of the particle size, the opposite relationship. The D value of No. 6 soil sample is the 
largest because of its relatively high proportion of fine-grained materials.
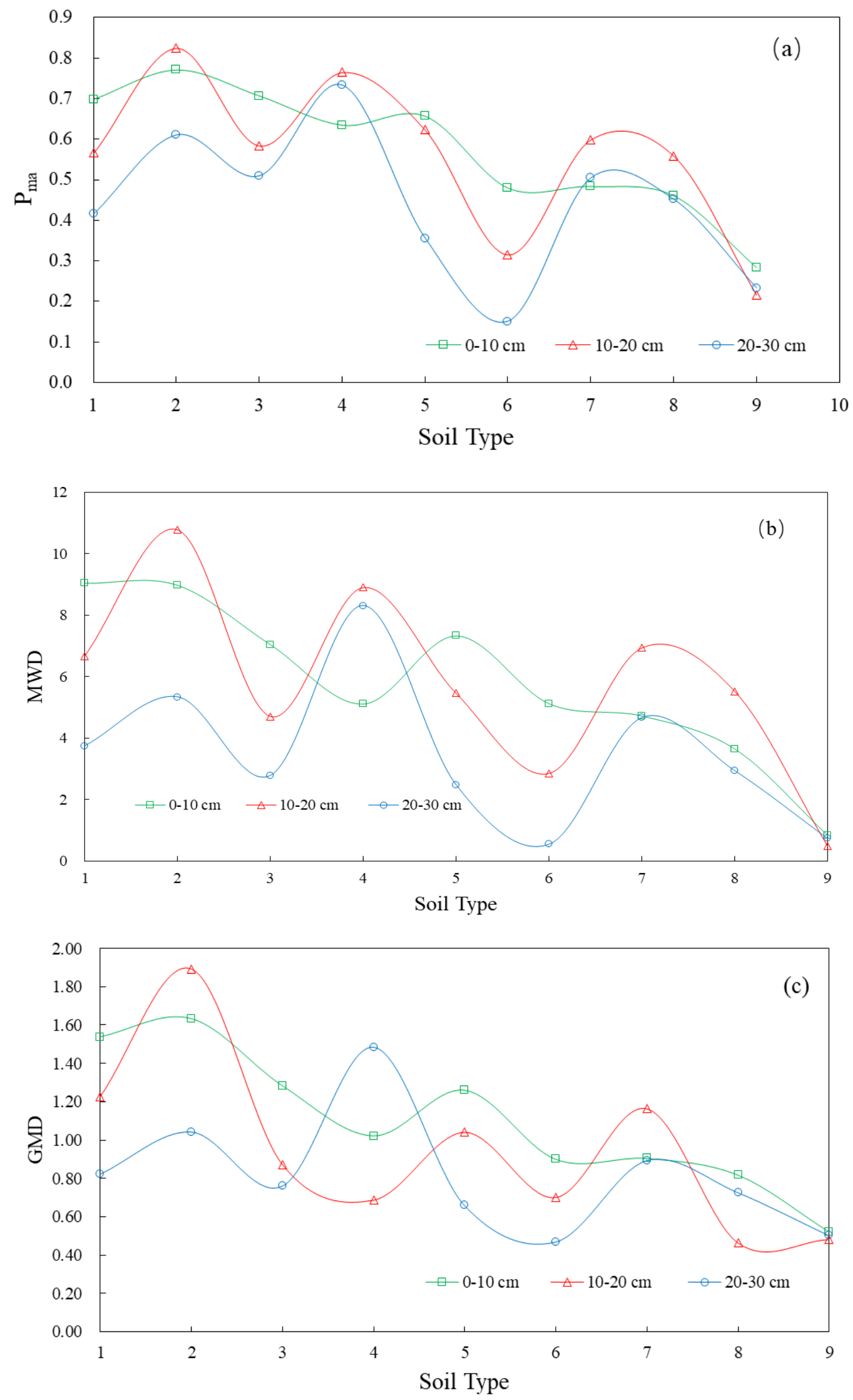

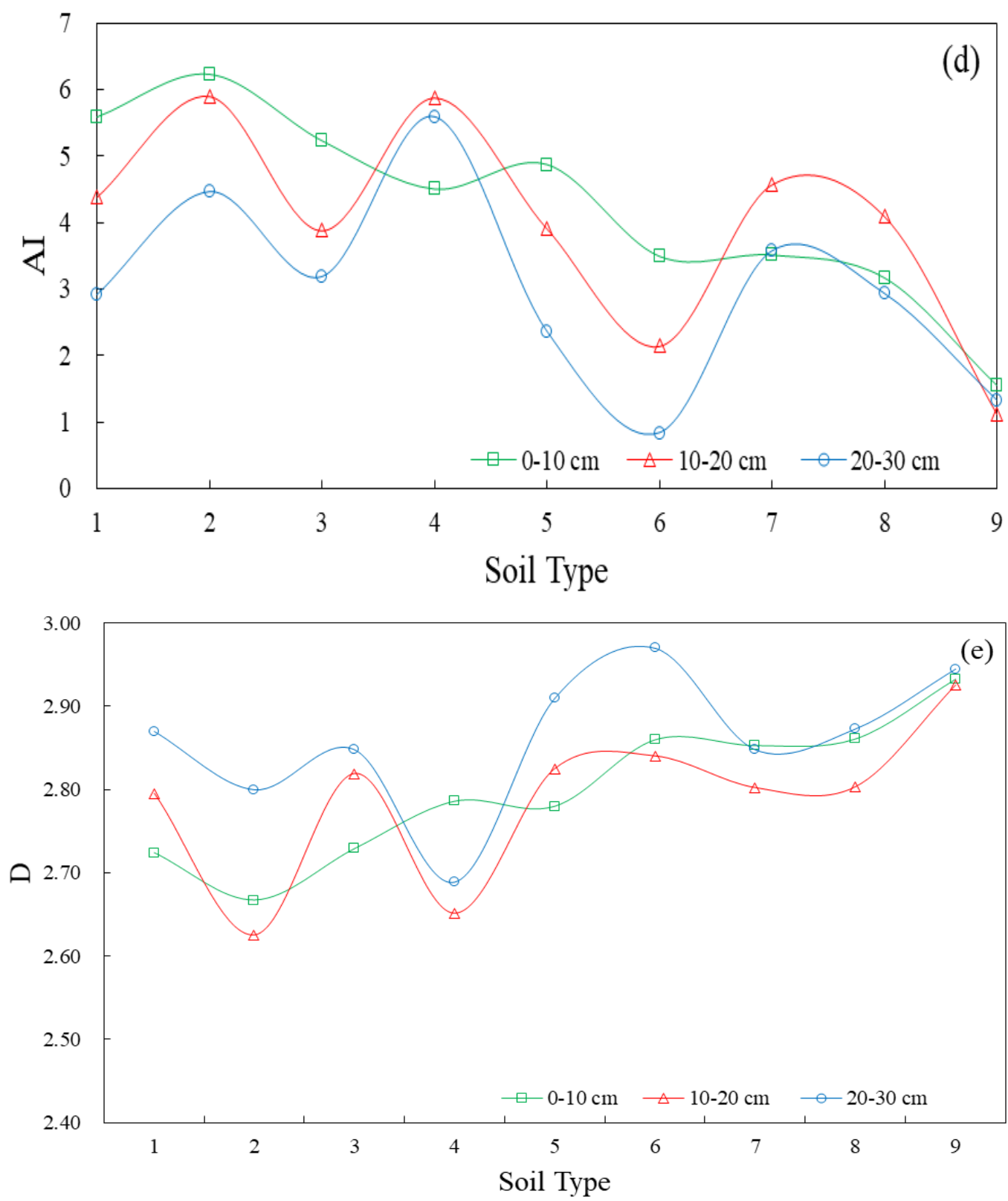

Fig 1. Distribution characteristics of each index of $0-30 \mathrm{~cm}$ soil aggregate

\subsection{Correlation of each stability index of aggregate}

As shown in Fig.2 (a-e), Preliminary analysis of the correlation between the 5 indicators of 0$30 \mathrm{~cm}$ soil layer samples. It can be seen from the figure that the correlation between the soil samples of each layer is relatively significant, the difference is that the correlation coefficient is different between different soil samples and different layers. In which, $\mathrm{P}$ has a positive linear relationship with MWD and AI values, and the correlation coefficients are 0.9517, 0.8901, 0.8854, 0.9849, 0.9608, 0.9843, as show in Fig.2 (e, d), the formula is as follows:

$$
y=a x+b
$$


Where, the $\mathrm{a}$ and $\mathrm{b}$ are the coefficient.

However, as shown in Fig.2 (c), P and D values show a negative linear correlation, that is, the higher the P, MWD, and GMD values are, the more stable the soil structure is. The smaller the D value, the smaller the dispersion of soil aggregates and the stronger the soil agglomeration. The D value has an opposite relationship with the $\mathrm{P}$ value, indicating that in the large aggregates, the large aggregates may contain more cementing substances, have strong polymerization and more important contribution to maintaining soil stability.

As shown in Fig.2 (a), the fitting of GMD and MWD found to show an exponential function relationship, the correlation coefficients are $0.98,0.98$ and 0.46 , the formula is as follows:

$$
y=a e^{b x}
$$

Where, the $a$ and $b$ are the coefficient.

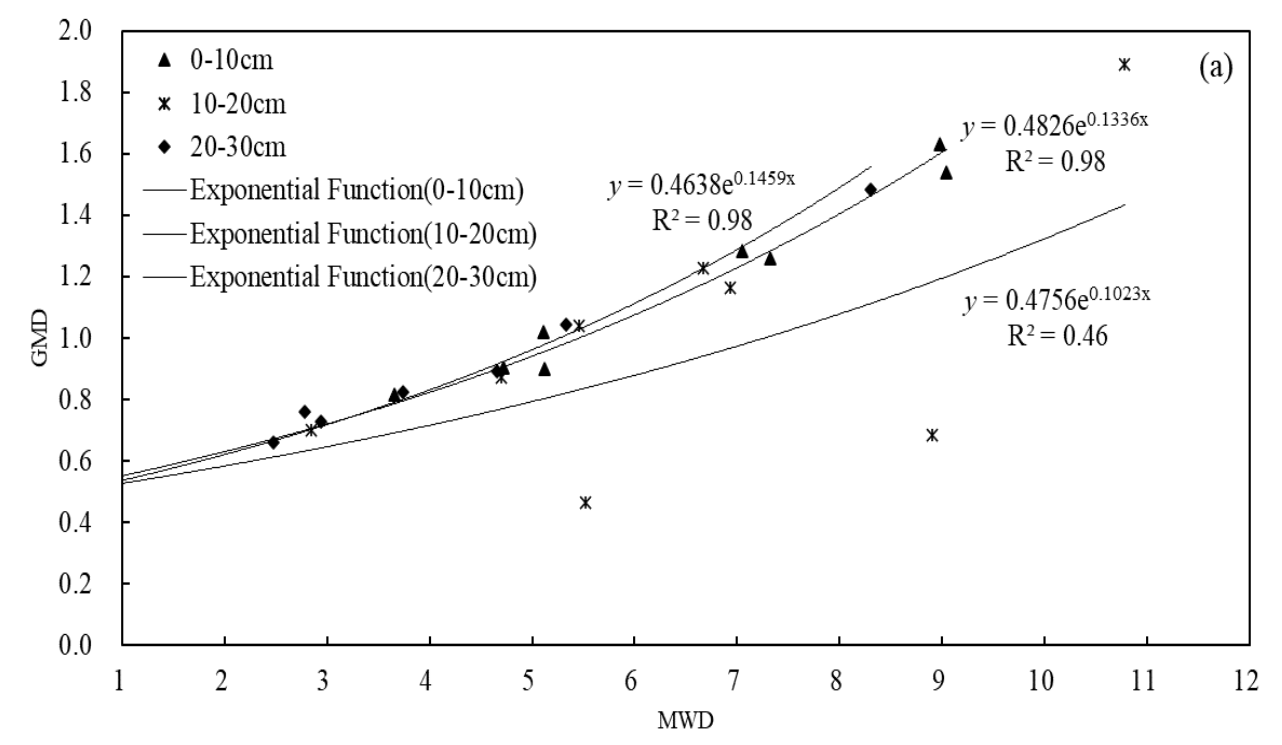



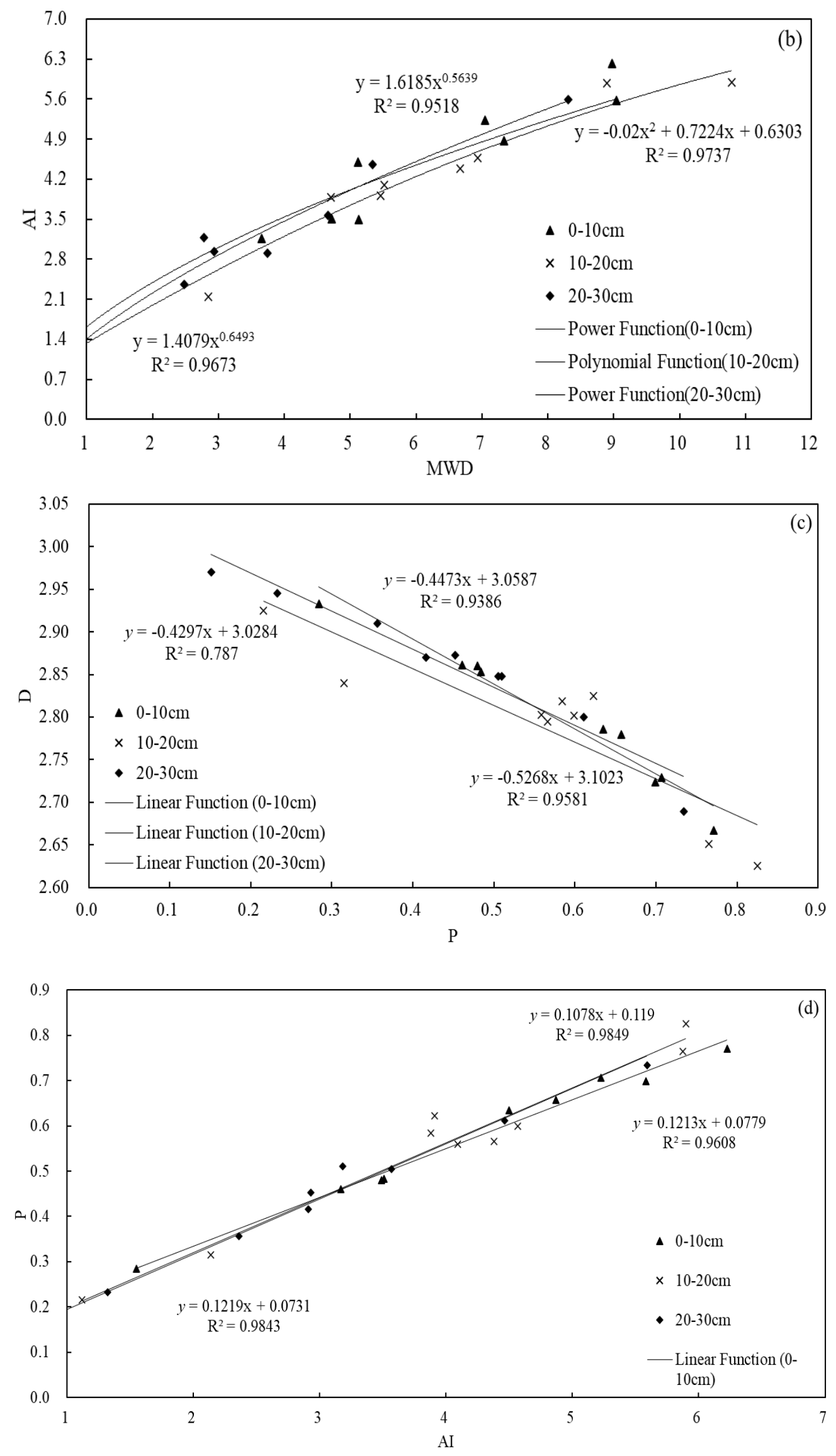


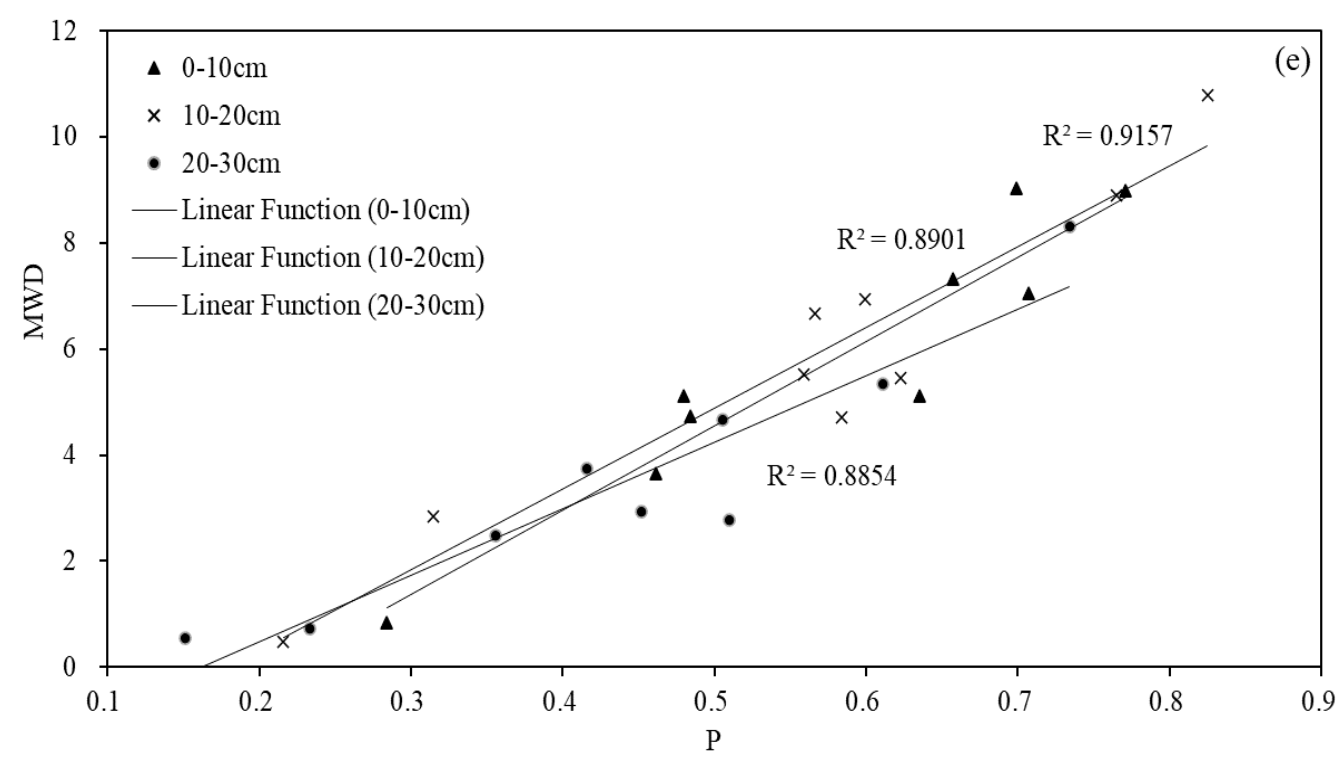

Fig 2. Correlation between granularity parameters

As shown in Fig.2 (b), the fitting of AI and MWD found to show a power function and polynomial function relationship, the correlation coefficients are $0.9518,0.9673$ and 0.9737 , the formula is as follows:

$$
\begin{gathered}
y=a x^{b} \\
y=-a x^{2}+b x+c
\end{gathered}
$$

Where, the $\mathrm{a}$ and $\mathrm{b}$ and $\mathrm{c}$ are the coefficient.

The correlation coefficients of the above indicators are relatively high, most of which are greater than 0.95 , and a very few are about 0.8 , which shows that the indicators can be substituted for each other. In the subsequent analysis, a certain index can be used to indicate the particle size distribution characteristics of the agglomerates.

\subsection{Correlation of each stability index of aggregate}

As shown in Figure 3, the soil erosion resistance coefficients of the $0-30 \mathrm{~cm}$ soil layer samples are calculated. The difference from Section 3.1 is that this issue will be further explained. Six typical soil samples are selected.

For the No. 1 soil sample, the $0-10 \mathrm{~cm}$ depth has the largest erosion resistance coefficient and the largest erosion energy consumption, respectively 51.12 and 5.74; with the increase of depth, the erosion resistance coefficient and erosion energy consumption appear at $10-20 \mathrm{~cm}$ and $20-30 \mathrm{~cm}$, the decreasing trend is 2.46 and 0.29 . The impact coefficients of samples No. 3 and No. 4 at $0-10 \mathrm{~cm}$ 
are relatively small, which is mainly due to the surface soil is loosen, which leads to large runoff sand content and low scour resistance, the erosion energy consumption is correspondingly small, only for 0.33 and 0.56 .
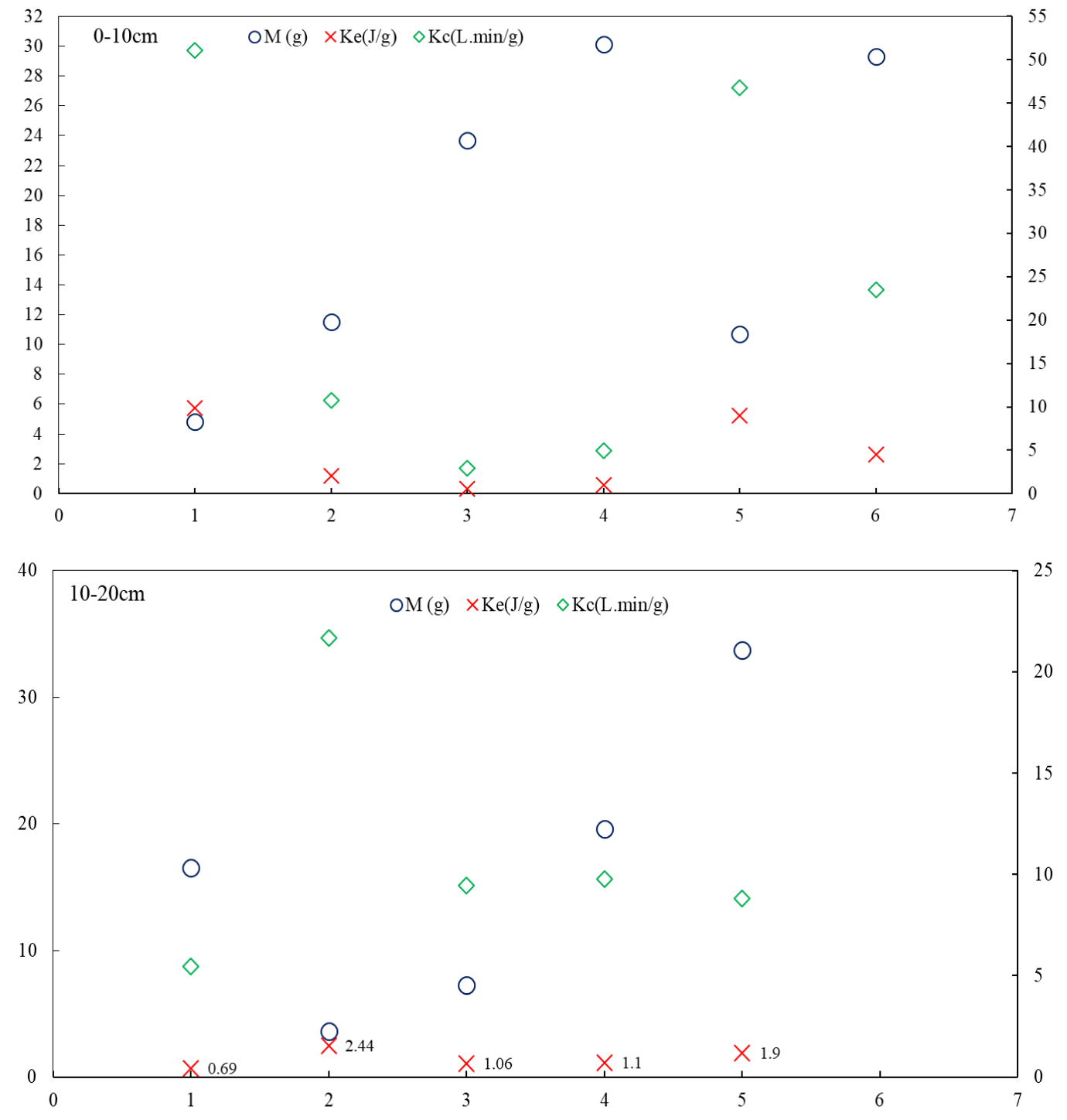


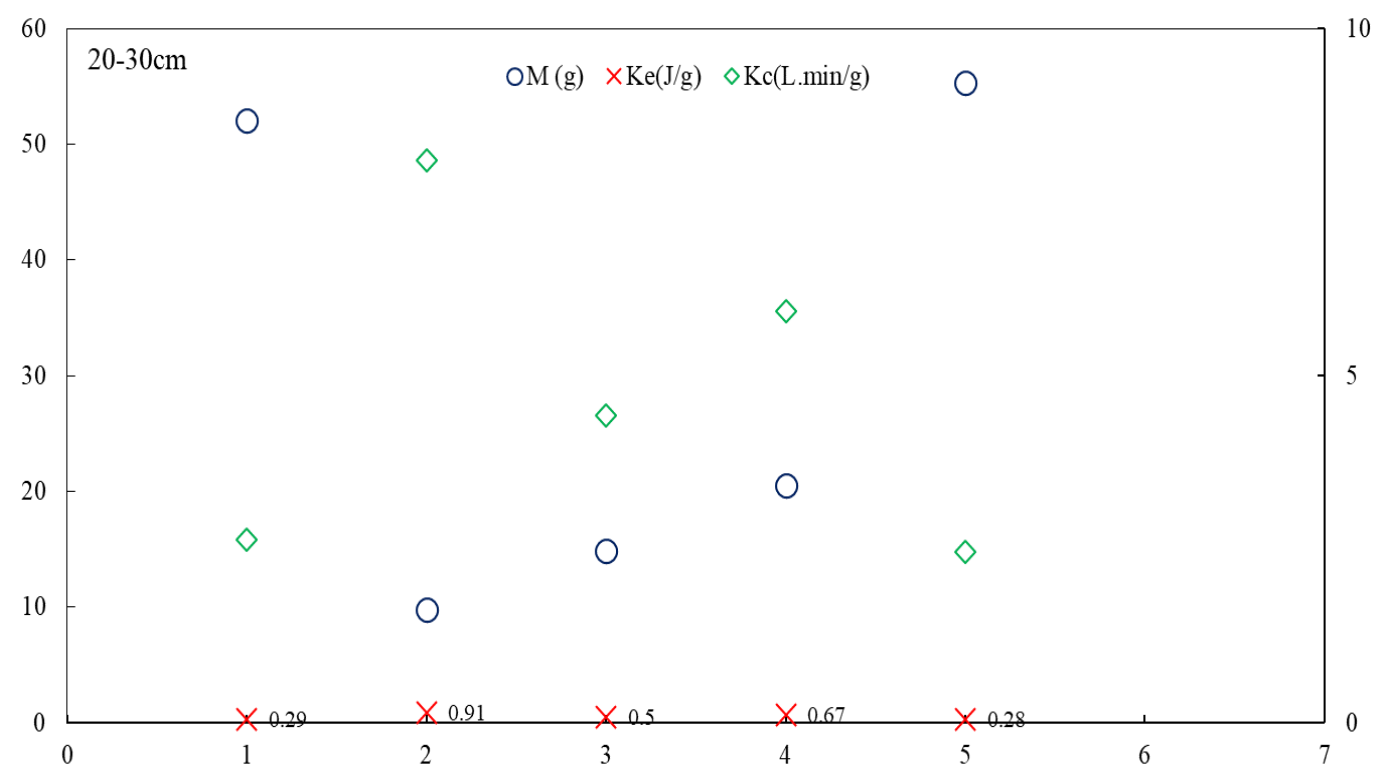

Fig 3. Scatter plot of impact resistance

The influence coefficient of other soil samples varies with different depths. The influence coefficient $\mathrm{K}$ value of soil sample No. 2 is the largest at $10-20 \mathrm{~cm}$ and the smallest at $20-30 \mathrm{~cm}$. Soil sample No. 5 has K value at $0-10 \mathrm{~cm}$. The largest is about 46.75 ; samples No. 3 and No. 4 have the largest $\mathrm{K}$ values at $10-20 \mathrm{~cm}$, which are 9.43 and 9.78 respectively, the scouring energy consumption shows the same rule.

During the impact test of different samples, as the water flow soaked and scoured the soil sample continuously, the binding force between soil particles gradually decreased, and the holding capacity of some root systems to the soil gradually weaken. When the water flow energy accumulated to a certain extent, the holding system of some soil blocks instantly collapsed, resulting in a sharp decline in soil erosion resistance; while the remaining soil samples became relatively stable due to the interaction of soil and root system, and the soil erosion resistance ability suddenly increased subsequently.

It can be seen from the order of appearance of the anti-scouring peaks in different samples and different depth layers that most of them are in the $20-30 \mathrm{~cm}$ soil layer, and the root density has a high correlativity. Therefore, after the relatively loose sediment on the surface of some parts, the root system hold the remaining soil firmly, even if the water continues to wash away the soil particles, there will be less lose. This is also the main reason for the increase in the impact resistance value at the end of the test.

Tab 2. CV value of soil anti-scouring coefficient 


\begin{tabular}{|c|c|c|c|c|c|}
\hline \multirow{2}{*}{ Deepth } & \multicolumn{5}{|c|}{ Soil type (Confidence 95\%) } \\
\hline & 1 & 2 & 3 & 4 & 5 \\
\hline $0-10 \mathrm{~cm}$ & $0.97^{* *}$ & $1.45^{* *}$ & $0.81^{* *}$ & $1.21^{* *}$ & $1.92^{* *}$ \\
\hline $10-20 \mathrm{~cm}$ & $0.74^{* *}$ & $0.6^{* *}$ & $0.56^{* *}$ & $1.03^{* *}$ & $0.57^{* *}$ \\
\hline $20-30 \mathrm{~cm}$ & $0.52^{* *}$ & $0.7^{* *}$ & $0.54^{* *}$ & $1.16^{* *}$ & $0.49^{* *}$ \\
\hline
\end{tabular}

As shown in Table 2, the maximum CV value is 1.92 and the minimum value is 0.49 . The significant difference between the $\mathrm{CV}$ values indicates that the scourability coefficients of different soil samples have a high degree of dispersion. $0-10 \mathrm{~cm}$ surface soil, the CV value of samples 1-5 are the maximum, the $\mathrm{CV}$ value of $10-20 \mathrm{~cm}$ is obviously reduced, the maximum value is only 1.03 , the minimum value is 0.56 , which is relatively large. The spatial variability of this layer of soil is still very strong. The CV value of $20-30 \mathrm{~cm}$ is low in some samples, and the decreasing trend is not obvious in some samples. The maximum value is 1.16 and the minimum value is 0.49 . This shows that the soil erosion resistance coefficient is a soil property with strong variability.

\section{Disscussion}

Soil fractal dimension (D), mean weight diameter (MWD) and geometric mean diameter (GMD) reflect the influence of soil water-stable aggregate content on soil structure and stability. D, MWD, GMD three indicators can be used as the evaluation index of the stability of soil water-stable aggregates, among which the fractal dimension D can not only reflect the size of soil particles, but also reflect the uniformity of the soil texture. The larger the Fractal dimension D value is, the greater the dispersion of aggregates and the worse the stability of soil structure. The results of this study show that the D values of sample 5 and sample 6 are significantly higher than other samples, mainly due to the greater interference from human activities and grazing, the impact of large damage to soil aggregates, low coverage, and natural factors such as rain erosion is greater; the D value of sample No. 4 is the smallest. The fractal dimension D values of soil samples under different forest and grass vegetation types are maintained at $2.69 \sim 2.92$, Castrignano et al. (1999) proposed that when D was close to 2 , it indicated that the aggregates were mainly large in size. As the value of D increased, the number of small-level aggregates in the soil increased. This research confirms this point of view. Sample No. 4 has a small D value, and the largest aggregate structures. Samples No. 5 and 6 have a large D value and a high proportion of micro aggregates. 
First, due to the drastic decrease in root biomass, soil erosion resistance is significantly reduced. For example, the impact resistance of No. 5 soil sample is the highest in the surface layer, but is lower in the 10-30 cm layer, which is about half of the surface layer, and the decline is larger. It is inferred from that the root system has little effect on the soil layer below $10 \mathrm{~cm}$, the content of soil cement is low, the aggregate structure is weak, and it cannot resist runoff erosion. The soil moisture content in the sample collection area is relatively low, resulting in poor root development. Although there are dense roots on the surface of the soil, which results in a relatively high erosion resistance of the soil, the erosion resistance below the dense root layer is still rapidly decreasing. Secondly, the soil erosion resistance of different restoration methods is also characteristic under the surface layer, and the soil erosion resistance below the surface layer may be higher than the surface layer, because the properties of the soil are changed after man-made disturbance. As mentioned in Section 3.1, the MWD values of soil aggregates below the surface of No. 2 and No. 4 soil samples are higher than those of the surface, which also indicates that the soil erosion resistance below the surface of the area where such soil samples are located is relatively stronger than that of the surface. For a wide range of slopes dominated by herbaceous plants, the dense layer of roots on the surface is the only barrier against runoff erosion, and the erosion resistance of the soil below the surface will be drastically reduced. Therefore, to prevent slope erosion is to strengthen the surface. The protection and planting of herb roots should also insist on not disturbing the topsoil and focus on natural restoration and succession.

In terms of the coefficient of variation of soil, scour resistance is a soil property with strong variation. In other words, when the sampling point is small, the data cannot accurately represent the overall situation of the sample site. In addition, the obtained results have a high degree of dispersion, it is impossible to determine what interval the average value of a certain soil sample is located in. Nevertheless, the approximate range of the soil anti-scourability coefficient in this study has obtained ideal results. The maximum values in the results of scour resistance come from samples with special mulching conditions on the ground. In fact, they represent the highest soil scour resistance of the soil in the study area. However, the minimum values of soil scour resistance are those with little surface coverage such as agricultural land. It is reflected in the $20-30 \mathrm{~cm}$ soil layer. In future research, we will continue to increase the selection of samples and conduct comprehensive 
tests of soil erosion resistance for more land use types.

\section{Conclusion}

The influence of vegetation on soil water-stable aggregates is generally in the depth range of 0-30 cm. No. 2 soil sample has the largest water-stable large aggregates, MWD and GMD values, the best soil structure, and the strongest anti-erosion ability. The No. 9 soil sample has the smallest value of various indicators of soil water-stable aggregate stability, the soil structure is the worst and erosion resistance are the most serious. There is a good linear relationship between soil fractal dimension D of different land use in small watershed and aggregate index. D not only reflects the quantitative characteristics of large aggregates but also indicates the strength of soil erosion resistance. The variation coefficient of the water-stable aggregates in each soil sample shows a trend of gradually becoming smaller as the depth increases.

In view of the management of different land use methods, the afforestation area and natural restoration grassland of the Loess Plateau should be mainly protected. The cultivated land in the form of stepped stone ridges can increase the number of large aggregates and improve the stability of soil aggregates, thereby slowing down the water and soil loss, preventing and controlling of slope erosion.

\section{Declaration of Competing Interest}

The authors declare that they have no known competing financial interests or personal relationships that could have appeared to influence the work reported in this paper.

\section{Acknowledgements}

This work was supported by the "National Natural Science Foundation of China (41905009)" and "Tianshan Youth Talents (Xinjiang)" Plan Project (2019Q037), the Second Tibetan Plateau Scientific Expedition and Research (STEP) program (grant no.2019QZKK010206) and General scientific research project of Xinjiang Meteorological Bureau (MS201907).

\section{Reference}

Amezketa E. Soil aggregate stability: A review [J]. Journal of Sustainable Agriculture, 1999, 14(2/3): $83-151$

Bronick C J, La 1 R. Manuring and rotation effects on soil organic carbon concentration for different aggregate size fraction son two soils in north-eastern Ohio, USA. Soil and Tillage Research, 2005 , 
81: 239-252 .

Bronick, C.J., \& Lal, R. (2005). Soil structure and management: a review. Geoderma, 124, 3-22.

Castrignano A, Stelluti M. Fractal geometry and geostatistics for describing the field variability of soil aggregation[J], Journal of Agricultural Engineering Research, 1999, 73(1): 13-18.

Fattet M, Fu Y, Ghestem M, et al. 2011. Effects of vegetation type on soil resistance to erosion: Relationship between aggregate stability and shear strength. Catena, 87: 60-69.

Fattet M, Fu Y, Ghestem M, et al. 2011. Effects of vegetation type on soil resistance to erosion: Relationship between aggregate stability and shear strength. Catena, 87: 60-69.

Fu, B.J., Liu, Y., Lü, Y.H., He, C.S., Zeng, Y., Wu, B.F., 2011. Assessing the soil erosioncontrol service of ecosystems change in the Loess Plateau of China. Ecol. Complex. 8 (4),284-293.

Hossain, M.F., Chen, W., Zhang, Y., 2015. Bulk density of mineral and organic soils in the Canada's arctic and sub-arctic. Inf. Process. Agric. 2, 183-190.

Jacobs, M., Sulman, B., Brzostek, E., Feighery, J., Phillips, R., 2018. Interactions among decaying leaf litter, root litter and soil organic matter vary with mycorrhizal type. J. Ecol. 106, 502-513.

Karami, A., Homaee, M., Afzalinia, S., Ruhipour, H., Basirat, S., 2012. Organic resource management: impacts on soil aggregate stability and other soil physico-chemical properties. Agric. Ecosyst. Environ. 148, 22-28.

Li Z X, Cai C F, Shi Z H, et al. Aggregate stability and its relationship with some chemical properties of red soils in subtropical China. Pedosphere, 2005, 15(1):129-136 .

Li, Q., Liu, G.B., Zhang, Z., Tuo, D.F., Miao, X.R., 2016. Structural stability and erodibility of soil in an age sequence of artificial robinia pseudoacacia on a hilly Loess Plateau. Polish J. Environ. Stud. 25, 1595-1601.

Ola A, Dodd IC, Quinton JN. 2015. Can we manipulate root system architecture to control soil erosion. Soil, 1: 603-612.

Pinheiro E F M, Pereira M G, Anjos L H C. Aggregate distribution and soil organic matter under different tillage systems for vegetable crops in a Red Latosol from Brazil. Soil and Tillage Research, $2004,77: 79-84$

Reubens B, Poesen J, Frédéric Danjon, et al. 2007. The role of fine and coarse roots in shallow slope stability and soil erosion controlwith a focus on root system architecture: a review. Trees, 21: 385- 
402

Saifuddin M, Osman N, Rahman MM, et al. 2015. Soil reinforcement capability of two legume species from plant morphological traits and mechanical properties. Current Science, 108: 1340-1347. Saifuddin M, Osman N, Rahman MM, et al. 2015. Soil reinforcement capability of two legume species from plant morphological traits and mechanical properties. Current Science, 108: 1340-1347. Shinjo, H., Fujita, H., Gintzburger, G., Kosaki, T., 2000. Soil aggregate stability under different landscapes and vegetation types in a semiarid area in northeastern Syria. Soil Sci. Plant Nutr. 46, 229-240.

Six J, Bossuyt H, Degryze D, et al. A history of research om the link between aggregates, soil biota, and soil organic matter dynamics. Soil and Tillage Research, 2004,79(1):7-31

Steel, R.G.D., Torrie, J.H., 1980. Duncan's new multiple range test. Princ. Proced. Stat.187-188. Su, Z.A., Zhang, J.H., Nie, X.J., 2010. Effect of soil erosion on soil properties and crop yields Sun, F.F., Lu, S.G., 2014. Biochars improve aggregate stability, water retention, and porespace properties of clayey soil. J. Plant Nutrit. Soil Sci. 177, 26-33.

Wang, Y., Zhang, J.H., Zhang, Z.H., 2015b. Influences of intensive tillage on water-stable aggregate distribution on a steep hillslope. Soil Tillage Res. 151, 82-92.

Yoder R E. A direct method of agreegate analysis of soils and a study of the physical nature of erosion lossess.Journal of the American Society Agronomy,1936,28:337-351

Zhang G S, Chan K Y, Oates A, et al. Relationship between soil structure and runoff/soil loss after 24 years of conservation tillage .Soil and Tillage Research, 2007, 92(1):122-128 .

Zhao, D., Xu, M.X., Liu, G.B., Yao, X., Tuo, D.F., Zhang, R.R., Xiao, T.Q., Peng, G.Y., 2017.

Quantification of soil aggregate microstructure on abandoned cropland during vegetative succession using synchrotron radiation-based micro-computed tomography. Soil Tillage Res. 165, 239-246.

Zhou H, Peng X, Peth S, et al. Effects of vegetation restoration on soil aggregate microstructure quantified with synchrotron based micro com-puted tomography.Soil and Tillage Research, 2012, 124: $17-23$.

Zhu, G.Y., Deng, L., \& Shangguan, Z.P., 2018. Effects of soil aggregate stability on soil N following land use changes under erodible environment. Agriculture, Ecosystems \& Environment, 262, 18-28. Zhu, G.Y., Shangguan, Z.P., Deng, L., 2017. Soil aggregate stability and aggregate-associated 
carbon and nitrogen in natural restoration grassland and Chinese red pine plantation on the Loess

Plateau. Catena 149, 253-260. 